\title{
Os desafios da participação e da cidadania nos sistemas de saúde
}

\author{
The challenges of citizenship and participation \\ in the health systems
}

\begin{abstract}
The themes of citizen participation and citizenship have assumed great relevance in public policy in most countries of the world. In this article, after briefly summarizing the main stages of development of the concept of citizenship, the prominence of social participation as a practice of citizenship will be depicted. Next, the potential and limits of deliberative approaches established to promote new strategies of citizens' participation in health will be analyzed. The paper will then focus on critical aspects that contribute to reducing or hindering the exercise of citizenship rights, including: the issue of representation underpinning the citizen participation methods; the issue of the influence of participatory devices in decision-making processes; and the limited experience and interest in assessing the effectiveness of citizen participation in the health sector.
\end{abstract}

Key words Citizens' participation, Citizenship, Health systems, Deliberative approaches, Evaluation of participation
Resumo Os temas da participação cidadã e da cidadania têm assumido grande relevância nas políticas públicas da maior parte dos países do mundo. Neste artigo, após ter brevemente resumido as principais etapas do desenvolvimento do conceito de cidadania e ter ilustrado a preeminência da participação social como sua prática, serão analisadas as potencialidades e os limites das abordagens deliberativas utilizadas para promover novas formas em saúde. Sucessivamente serão enfocados outros aspetos críticos que contribuem para reduzir o exercício dos direitos de cidadania, nomeadamente: a questão da representatividade, que subjaz aos métodos de participação dos cidadãos; o tema da influência da participação nos processos de decisão; a limitada experiência e o escasso interesse em avaliar a efetividade da participação no sector da saúde. Em conclusão, serão focalizados os principais desafios da participação e da prática da cidadania nos sistemas de saúde. Palavras-chave Participação dos cidadãos, Cidadania, Sistemas de saúde, Abordagens deliberativos, Avaliação da participação 


\section{Introdução}

Os temas da participação e da cidadania têm assumido grande relevância nas democracias ocidentais, tendo-se multiplicado, nos últimos anos, as iniciativas de participação provenientes da sociedade civil. O denominador comum destas iniciativas tem sido o de exercer uma forte pressão sobre o setor público, com o objetivo de reformular o sistema de direitos sociais, entendidos não mais como conjunto de direitos planejados e prestados pelo estado, mas como demanda de contribuição ativa na definição das políticas sociais e serviços públicos. Esta segunda tradição de cidadania promove um modelo de participação ativa dos cidadãos nas instituições e nos serviços públicos ${ }^{1-3}$. De fato, a partir dos últimos anos do seculo XX, houve uma mudança substancial na abordagem à cidadania: de um discurso baseado em um conjunto de direitos civis, políticos e sociais, de acordo com a elaboração teórica de Marshall ${ }^{4}$, para um conceito de cidadania que vai além da reivindicação dos direitos consagrados na Constituição.

A nova perspetiva de cidadania, definida como "cidadania ativa", tornou-se uma dimensão importante da política social e de saúde do governo do Partido Trabalhista na Grã-Bretanha desde o fim da década de 90 , em oposição ao sentido tradicional de cidadania ${ }^{5}$. Embora não se deva subestimar as críticas de alguns autores britânicos à nova abordagem ${ }^{6,7}$, considerada uma estratégia para legitimar as reformas econômicas e gerenciais introduzidas no sistema de saúde nos anos 90. Para Milewa et al. ${ }^{8}$, a ênfase na participação comunitária dos governos conservadores e, sucessivamente, também dos governos do partido trabalhista, reflete, na verdade, o reforço do protagonismo dos gestores (active management) no sistema de saúde, ao invés de promoção de "cidadania ativa" (acitve citizenship). Este processo, conforme Calnan e Gabe9, "deu mais poder aos gestores ao invés de aos pacientes".

No entanto, apesar de algumas formas de retórica política sobre o envolvimento de usuários e pacientes, o novo sentido de cidadania põe ênfase na comunidade, bem como nas obrigações do indivíduo, e promove um modelo de participação ativa dos cidadãos nas instituições e serviços públicos. Nos últimos 15 anos, este debate tem-se expandido na maioria dos países ocidentais. Nesse sentido, aumentou a demanda para uma melhor qualidade da atenção à saúde, para uma maior personalização e humanização dos cuidados a prestar e para a valorização da voz dos usuários. Ao mesmo tempo, foram introduzidas uma série de disposições destinadas a proteger e ampliar os direitos individuais dos pacientes.

A Organização Mundial da Saúde tem reiteradamente apoiado esta estratégia, enfatizando e promovendo a participação dos cidadãos em todos os documentos publicados nos últimos anos. A participação e o empoderamento dos cidadãos tornaram-se palavras-chave nos textos de reforma da maioria dos países. Tem sido apontada, portanto, a necessidade de incrementar a responsabilidade e transparência das novas formas de gestão dos serviços de saúde por meio de instâncias de envolvimento e participação dos usuários. Entretanto, os resultados de inúmeras pesquisas indicam que, apesar das boas intenções e de alguns esforços louváveis empreendidos, a participação, por várias razões, ainda tarda em entrar na praxis dos serviços de saúde.

Neste artigo, após ter brevemente resumido as principais etapas do desenvolvimento do conceito de cidadania e após ter ilustrado a preeminência da participação social como prática da cidadania, serão analisadas as potencialidades e os limites das abordagens deliberativas utilizadas para promover novas formas de cidadania em saúde. Sucessivamente serão enfocados outros aspetos críticos que contribuem para limitar ou obstaculizar o exercício dos direitos de cidadania, nomeadamente: a questão da representatividade, que subjaz aos métodos de participação dos cidadãos e os temas da influência dos dispositivos participativos e da escassez de estudos avaliativos.

\section{Participação social como prática da cidadania}

O primeiro conceito de cidadania a que nos referimos - definido como um conjunto de direitos garantidos progressivamente aos membros da sociedade - foi desenvolvido por Marshall ${ }^{4} \mathrm{em}$ seu famoso livro publicado em 1950, Citizenship and Social Class, e incluía três dimensões:

1. Cidadania civil, os direitos de liberdade da pessoa que tiveram um desenvolvimento significativo no século XVIII;

2. Cidadania política, ou os direitos de participar na vida política, conquistados pelas classes trabalhadoras no curso da luta pela igualdade política no século XIX; e

3. Cidadania social, que consiste no reconhecimento e ampliação durante o século XX de uma série de direitos sociais em períodos de desemprego e de doença, para permitir às pessoas participar do bem-estar econômico e social da comunidade. 
Apesar da sua grande influência, a perspetiva teórica de Marshall foi muito criticada ${ }^{10-12}$. Foi criticada por sua abordagem evolutiva à cidadania que prefigura a existência de uma cadeia sequencial entre direitos civis, políticos e sociais muito rígida e incapaz de compreender outros caminhos para a cidadania ${ }^{10,12}$; por não ter considerado o contexto mais amplo dentro do qual desenvolveu-se a política de bem-estar na Grã-Bretanha durante o período da pós-guerra; por ter analisado a cidadania como um processo irreversível nas sociedades contemporâneas, enquanto a experiência tem evidenciado que os direitos do Estado-Providência são reversíveis e não garantidos uma vez por todos (como está demostrando a crise financeira que está desestruturando o estado social dos países da Europa do sul); por ter adotado uma teoria da cidadania sem ter desenvolvido, em paralelo, uma teoria do Estado; por deixar de enfatizar a ideia de que, historicamente, o crescimento da cidadania social foi o resultado de violência e ameaças de violência que levaram o Estado na área social como um estabilizador do sistema social ${ }^{11}$.

Nesta linha crítica é interessante a análise de Carvalho ${ }^{12}$ que destaca como ainda hoje muitos direitos civis, que representam a base da sequência de Marshall, são inacessíveis à maioria da população, embora isso não tenha impedido a abertura de novos caminhos para a cidadania, "como demostram os casos da Inglaterra, da França e da Alemanha”. Também no Brasil, realça Carvalho ${ }^{12}$, a cronologia desenhada por Marshall foi invertida: antes vieram os direitos sociais, depois os direitos políticos e finalmente os direitos civis.

De uma perspetiva teórica radical, alguns estudiosos reivindicaram a ampliação da tríade de direitos reconhecidos no conceito de cidadania (civil, política e social), para incluir outros direitos e outras demandas. Uma abordagem alternativa à teoria da cidadania, por exemplo, surgiu na década de 90 a partir do movimento feminista e de outros movimentos sociais, e defendeu a necessidade de remover os mecanismos que excluem as demandas das minorias e grupos marginalizados ${ }^{13}$. Neste prisma são interessantes as considerações de Young ${ }^{14}$ : "No final do século $\mathrm{XX}$, quando os direitos de cidadania foram formalmente estendidos a todos os grupos nas sociedades capitalistas liberais, alguns grupos ainda se sentem tratados como cidadãos de segunda classe". Em outras palavras, Young ${ }^{14}$ critica a cidadania universal, baseada na ideia de assimilação e reivindica uma "cidadania diferenciada" como a melhor estratégia para alcançar a inclusão social e a participação de todos. O reconhecimento das diferenças, aponta a autora, não reduz a função integradora da cidadania, mas facilita a inclusão dos direitos de grupos multiculturais e desfavorecidos.

Outros teóricos alargaram ainda mais o âmbito dos direitos previstos por Marshall, exigindo o reconhecimento - entre os direitos fundamentais do cidadão - da mesma participação nos processos de decisão nas esferas social, econômica e cultural. Segundo Barbalet ${ }^{15}$, os direitos sociais representam as pré-condições da participação. Esta perspetiva de análise tenciona promover uma forma mais ativa dos direitos de cidadania do que os tradicionalmente associados com o estado do bem-estar do pós-guerra, através da promoção de estratégias para envolver os usuários, e do fortalecimento da responsabilização e transparência dos serviços públicos. Esta abordagem enfatiza a participação ativa dos cidadãos na governança do sistema de saúde e nas decisões políticas com a finalidade de promover o bem-estar de toda a comunidade.

O desenvolvimento da cidadania participativa tem sido interpretado como uma reação ao individualismo promovido pela abordagem liberal dominante à cidadania. Esta corrente, de acordo com Lister ${ }^{16}$, reduz as pessoas a indivíduos atomizados e passivos portadores de direitos. Assim, a cidadania, de projeto político coletivo, transforma-se numa atividade para o exercício dos interesses econômicos individuais. Sobre o mesmo tema, Crouch ${ }^{17}$ salienta que os direitos de cidadania podem ser adquiridos através da ação coletiva, enquanto "obtê-lo como clientes significa comprá-los".

$\mathrm{Na}$ era da biomedicina, da biotecnologia e da genética, nos últimos anos um novo tipo de cidadania está sendo reivindicado no campo da saúde, que alguns autores têm denominado 'cidadania biológica'18,19 ou 'justiça sanitária' ${ }^{20}$. Nesta nova era biológica, realça $\operatorname{Rose}^{18}$, nem todos têm igualdade de cidadania e existem diferentes ideias e práticas de cidadania que podem ser observadas na crescente importância dada a corporalidade e às "novas tecnologias que intervêm no corpo em níveis que vão desde o superficial (cirurgia estética) ao molecular (terapia genética)" ${ }^{\prime 18}$. Adriana Petrina $^{19}$, por exemplo, nos estudos realizados sobre o desastre nuclear de Chernobyl, tem desenvolvido o conceito de cidadania biológica para reivindicar os direitos dos cidadãos expostos às contaminações radioativas ao acesso aos cuidados médicos, ao apoio social e legal e ao ressarcimento dos danos. Neste prisma, a cidadania bio- 
lógica pode incorporar a demanda por formas de bem-estar social e a adoção ou interrupção de determinadas políticas ou ações ${ }^{18}$. A cidadania biológica e a justiça sanitária podem ser reivindicadas seja individualmente, mobilizando as redes de relacionamentos dentro e fora das instituições e organizações ${ }^{20} \mathrm{e}$ seja coletivamente por meio do ativismo de grupos e associações que possuem uma vasta experiência de mobilização e recusa do estado de pacientes passivos ${ }^{18}$.

Osler e Starkley ${ }^{21}$ propuseram uma definição multidimensional do conceito de cidadania ao introduzir uma terceira dimensão: a cidadania como um sentimento (feeling). Segundo os autores, a cidadania como status descreve a relação entre os indivíduos e o Estado, assim como o conjunto de direitos e garantias para proteger os cidadãos que, em troca, contribuem para a cobertura dos investimentos coletivos através dos impostos. A cidadania como sentimento se preocupa com o sentido de pertença à comunidade. Ainda quando os indivíduos têm o estatuto de cidadãos - apontam Osler e Starkley ${ }^{21}$ - há graus diferentes de identificação com os valores nacionais. Existem, de fato, várias barreiras formais e informais que dificultam a realização da cidadania plena, particularmente entre mulheres e certos grupos sociais e étnicos. A este respeito, bem conhecidas são as desigualdades sociais de saúde produzidas pelas barreiras econômicas e culturais. A cidadania como prática permite à pessoa agir tanto individualmente, como também em conjunto com outros, a fim de efetuar as mudanças necessárias ou influenciar os decisores. Nesta perspetiva, o objetivo da cidadania não pode se limitar ao simples exercício do direito de voto, mas deve também incluir a participação nas decisões que afetam a vida dos próprios cidadãos. Portanto, não é suficiente adquirir a titularidade dos direitos, mas é a participação ativa que permite que as pessoas exerçam os seus direitos. Mais do que uma identidade - observam Cornwall et al. ${ }^{22}$-, a cidadania é algo "que é posta em prática, criada e recriada de maneiras diferentes e em diferentes espaços", e intimamente ligadas às diferentes formas em que as pessoas se constituem como atores sociais no território onde agem.

Como pode ser observado a partir da análise dos autores consultados, o conceito de cidadania é carregado com valores e tem sido alvo de intenso debate entre os sociólogos e cientistas políticos. Para alguns, a cidadania envolve uma série de direitos individuais, enquanto para outros é vista como um conjunto mais amplo de responsabilidade social e civil. Duas tradições diferentes: uma destaca o indivíduo e seus direitos, a outra, a comunidade e as obrigações do indivíduo para ela; uma enfatiza a cidadania como um status, a outra a cidadania como prática.

Recentemente, tem avançado a ideia de conectar essas duas principais tradições de cidadania, que animaram e polarizaram o debate nos últimos anos. De acordo com Lister ${ }^{16}$, a cidadania como participação pode ser considerada uma expressão da ação humana (human agency) na arena política, mas é a cidadania como titularidade de direitos que dá às pessoas a capacidade de agir. Em outras palavras, ser um cidadão significa desfrutar os direitos necessários para a ação e para a participação social e política. Agir como cidadãos, realça Lister ${ }^{16}$, "envolve a realização de todo o potencial do status". No entanto, "quem não cumprir esse potencial não deixa de ser um cidadão". A experiência de participação, assinala Wharf Higgins ${ }^{23}$, reforça a capacitação pessoal. Através da participação na vida da comunidade. Ou seja, praticando cidadania, pode-se ganhar um senso de controle sobre a própria vida e um senso de pertencimento. Em essência, um sentimento de capacitação (empowerment).

Apesar da participação dos cidadãos ser amplamente reconhecida como uma dimensão fundamental da cidadania, os resultados obtidos até agora nessa área têm sido bastante modestos. $\mathrm{Na}$ verdade, nem todos os cidadãos têm os meios para fazer valer os seus direitos e vantagens de cidadania e muitas vezes aqueles que podem ser percebidos como os principais beneficiários da participação da comunidade nos cuidados de saúde são os menos propensos a se envolver nestas iniciativas ${ }^{23}$.

\section{O desafio da participação deliberativa: potencialidades e limitações}

$\mathrm{Na}$ última década, o debate sobre participação tem apontado a necessidade de adotar novas abordagens para reforçar a interação e o diálogo entre cidadãos e seus representantes, de uma parte, e profissionais e gestores, da outra parte. Em outras palavras, hoje em dia, a prioridade não é mais a de legitimar a participação dos cidadãos nos sistemas de saúde (preocupação advertida nos anos 80 e 90), mas a de melhorar a qualidade e a efetividade da participação, através da promoção de estratégia de inclusão e acesso em favor de determinadas categorias de cidadãos, que geralmente são excluídas não só dos processos de decisão, mas também da sociedade num sentido mais amplo. Neste sentido, nos últimos 
anos, os métodos deliberativos têm recebido um interesse crescente enquanto estratégia inovadora para fortalecer a participação cidadã. Na literatura sociológica e das ciências políticas dos países anglo-saxónicos, o termo 'deliberativo' expressa a possibilidade de debater e analisar, cuidadosamente junto com outros participantes, determinadas questões e aspetos críticos, mas não inclui necessariamente a participação direta nos processos de tomada de decisão. Ou seja, refere-se às dimensões normativas do diálogo e da busca do entendimento e do consenso. Enquanto no Brasil a função deliberativa dos Conselhos de saúde diz mais sobre o poder de tomar decisões vinculativas, decisões que podem ser alcançadas também sem consenso ${ }^{24-27}$. Neste prisma é interessante a análise de Avritzer ${ }^{28}$ sobre a evolução do "conceito decisionístico de deliberação para um conceito argumentativo de deliberação".

Por democracia deliberativa se entende aquele processo decisional baseado na discussão e análise - preferentemente em pequenos grupos - dos diversos argumentos colocados pelos participantes líberos e dotados de pares oportunida$\mathrm{des}^{29}$. Os métodos deliberativos, que representam uma forma de participação, oferecem aos indivíduos a oportunidade de expressar seus pontos de vista, conhecer e compreender as posições de outros participantes, identificar preferências e problemas compartidos, até chegar a adquirir um juízo fundamentado sobre temas de relevância pública. A prática deliberativa supõe obrigatoriamente um processo coletivo de tomada de decisão, em que os participantes interessados na discussão dos temas enfrentados têm a oportunidade de convergir sobre uma opinião compartilhada, dando voz e relevância a todos os argumentos apresentados. A democracia deliberativa focaliza, assim, os processos comunicativos entre decisores políticos e cidadãos, a formação das opiniões e das vontades que precedem a votação sobre uma determinada decisão.

Contudo, cabe destacar, como ressaltam Abelson et al. ${ }^{30}$, que deliberação é muito mais que uma simples discussão de assuntos. $\mathrm{O}$ processo deliberativo também se preocupa com o resultado da discussão, ou seja, das decisões e recomendações propostas e do processo que gera esse resultado.

A ideia de democracia deliberativa é muito antiga, embora nos últimos anos tenha obtido mais destaque graças a influência da obra de Jürgen Habermas ${ }^{31}$, em particular os conceitos de "situação discursiva ideal", "formação discursiva do consenso" e "ação comunicativa orientada ao entendimento". Esta perspetiva está suscitando um grande interesse também no setor sanitário, onde se percebe a necessidade de criar uma 'esfera pública' apropriada ${ }^{1}$, para incentivar o diálogo entre os diferentes atores do sistema de saúde. Entre os métodos mais utilizados para implementar os processos deliberativos importa destacar os seguintes: Júris de cidadãos, Workshops de cidadãos, Unidades de planejamento, Painéis de cidadãos, Conferências de consenso, Processos de votação deliberativa (deliberative poll) e Grupos focais deliberativos. Comum a todos eles é o elemento deliberativo que inclui alguns aspetos essenciais, como: prover as informações sobre o assunto em discussão a todos os participantes; descrever os assuntos analisados no idioma dos cidadãos comuns (ordinary citizens); considerar atentamente os pontos de vista dos outros participantes; estimular a discussão para alcançar o consenso ou para aproximar as diversas posições sobre o assunto.

Entre os benefícios dos processos deliberativos realçados, cabe assinalar os seguintes ${ }^{28,30,32-34}$ : a capacidade de desenvolver uma opinião esclarecida, a potencialidade para alterar as opiniões dos participantes; a capacidade de aumentar o nível de tolerância e compreensão entre grupos, para aceitar os diversos pontos de vista; um maior envolvimento dos cidadãos nas políticas de saúde; uma oportunidade para conhecer as necessidades de saúde e valorizar as próprias experiências; um mecanismo idôneo para produzir decisões coletivas e para aumentar a legitimidade das decisões. Enfim, há um grande otimismo acerca das potencialidades e efeitos positivos dos métodos deliberativos, tanto nos participantes como no sistema de saúde. Porém, são ainda poucos os estudos que têm examinado atentamente sua efetividade e capacidade de influenciar os decisores políticos ${ }^{30,35,36}$. Por exemplo, os resultados das avaliações dos Júri de Cidadãos (JC Citizens Juries) - um método deliberativo muito utilizado nos sistemas de saúde de Reino Unido, Canadá e Austrália e bastante conhecido em nível internacional - têm mostrado diversas potencialidades, mas também alguns pontos críticos ${ }^{37-39}$. Sem dúvida, o método de envolvimento adotado pelos JC representa um ponto de força. Muitos estudiosos têm destacado a sua "superioridade" em relação aos tradicionais dispositivos adotados no setor da saúde (questionários, grupos focais, conferências, etc.), em virtude da sua capacidade de estimular a reflexão dos jurados e elaborar recomendações para os gestores ${ }^{38}$. Entretanto, importa assinalar também alguns constrangimen- 
tos: a) não há garantia que as recomendações dos JC sejam adotadas pelas autoridades de saúde ${ }^{36-38}$. Isso significa que o modelo dos JC, como de outros modelos de participação consultiva, deixa os usuários fora da arena política, na espera que suas sugestões sejam incorporadas nos processos de decisão. b) Baixo nível de institucionalização no âmbito do sistema de saúde, tratando-se de uma forma de participação ocasional ativada por iniciativa das autoridades de saúde. A participação pública, como afirma Rigge ${ }^{40}$, não deve ser entendida como um exercício isolado (ad-hoc participation), mas como uma componente vital para garantir a qualidade do sistema de saúde. As avaliações até agora realizadas, sobre o envolvimento dos cidadãos ${ }^{32}$, têm evidenciado o valor da continuidade da participação (on-going participation). Somente desta forma é possível estabelecer as bases para o desenvolvimento de formas mais avançadas de participação e de cidadania em saúde. c) Os custos financeiros excessivos que comportam o planejamento e a execução dos $\mathrm{JC}^{37-39}$. De acordo com as estimativas de Iredale e Longley $^{38}$, a organização de um JC custa cerca de 25.000 libras, incluindo as despesas para recrutar os jurados, remunerar os testemunhos e os moderadores, e para transporte, alimentação e alojamento. d) Assimetria de poder. Alguns estudos têm mostrado que a centralidade do poder não foi redimensionada ${ }^{30} \mathrm{e}$ que os participantes interagem em situações e contextos caracterizados pela distribuição desigual de poder ${ }^{41}$. Tais investigações têm questionado um pré-requisito da democracia participativa, ou seja, a capacidade de excluir o poder do diálogo deliberativo e de reduzir as desigualdades entre os participantes. Essas desigualdades são geradas tanto pelas diferenças materiais e de classe entre os participantes quanto pela disparidade de informações e de conhecimentos entre peritos e cidadãos. Referindo-se à experiência do júri de cidadão de Bristol, Gooberman-Hill et al. ${ }^{39}$ mostraram que há uma clara assimetria de poder entre os patrocinadores do processo deliberativo (que detêm a informação) e os jurados.

A preocupação pela concentração das informações nos gestores e nos técnicos e pela relação assimétrica entre os conselheiros usuários e os demais representantes é um tema constantemente aflorado nas pesquisas realizadas com os Conselhos Municipais de Saúde no Brasi $1^{25,42-44}$.

\section{Representatividade e inclusão das instâncias de participação}

Outro aspeto problemático, já evidenciado pelas investigações realizadas nos anos noven$\mathrm{ta}^{2,45}$, refere-se à representatividade das instâncias de participação ativadas. Muitos estudos têm demonstrado que nem sempre os representantes dos usuários e as associações de pacientes conseguem ser representantes das necessidades de toda a população e, sobretudo, dos setores sociais mais desfavorecidos. É certo que, no caso da participação social, não se pode falar de representatividade no sentido próprio do termo, na medida em que não existem mecanismos formais de delegação, através dos quais grupos ou categorias de usuários escolhem seus representantes. No caso das associações de pacientes, por exemplo, como apontam Bovenkamp et al ${ }^{46}$, não existe uma seleção formal das associações que podem participar nos processos de tomada de decisões. Teoricamente, todas podem participar. Além disso, é difícil argumentar que tais fóruns podem representar a todos os cidadãos de uma determinada área ou a todos os usuários de um serviço, considerando a proporção limitada de pessoas e associações que participam ativamente nas atividades ${ }^{47,48}$. Nesse sentido, Contandriopoulos ${ }^{49}$ afirma que os participantes envolvidos em mecanismos de participação pública "são autodesignados ou nomeados através de procedimentos formais de representação débil". Na mesma linha, Lomas ${ }^{45}$ demonstra que os membros escolhidos para participar não são, do ponto de vista social e demográfico, representativos da comunidade. Neste caso, se trata de um déficit de "representação descritiva" ${ }^{50}$, que faz referência às características demográficas, tais como sexo, idade, etnicidade, educação e rendimento. Contudo, há que considerar também o déficit de "representação substancial" ${ }^{50}$, quando os membros designados - embora representem as diversas categorias da população ou da área geográfica - não perseguem os reais interesses daqueles que representam. De fato, como assinalam vários estudos brasileiros ${ }^{25,43,44,51,52}$, uma representatividade efetiva e responsável, supõe a ativação de canais de comunicação bidirecionais entre as pessoas nomeadas e sua base de apoio.

A situação não é melhor no caso dos métodos deliberativos cujas virtudes são também questionadas pelo déficit de representatividade que deveria constituir um elemento fundamental da democracia participativa. O envolvimento de pequenos grupos de participantes submete os processos deliberativos a fortes críticas ${ }^{30}$. Vá- 
rios estudos têm enfatizado o paradoxo da participação pública que poderia contribuir para o aumento das desigualdades de saúde, na medida em que os grupos sociais vulneráveis, os que Timotijevic e Raats ${ }^{53}$ definem cidadãos "difíceis de alcançar” (hard-to-reach citizens) - imigrantes, idosos, pessoas com problema de saúde mental e, em geral, as pessoas com escassas competências linguísticas - que participam menos que as pessoas formadas e mais integradas socialmente ${ }^{27}$. Existe o risco, que a deliberação pública se torne uma prática reservada aos grupos mais favorecidos, que assim podem consolidar suas posições sociais e adquirir uma maior dotação de capital social $^{34}$, reforçando os padrões existentes de exclusão social ${ }^{24}$.

O conceito de cidadania, incluindo o originalmente desenvolvido por Marshall ${ }^{4}$, implica um conjunto de direitos igualmente desfrutados por todos os membros da sociedade.

De acordo com Miller ${ }^{54}$, nos escritos de Marshall dos anos 50 se percebe a preocupação pelas desigualdades de classe e pelo seu impacto sobre a cidadania, que o autor observou na sociedade britânica da época. A este respeito, salienta Miller ${ }^{54}$, o conceito de cidadania em Marshall implica uma potencial distribuição do rendimento. Os cidadãos são de fato titulares de benefícios, tais como a saúde e a educação de seus filhos, que poderiam não ser capazes de suportar com os próprios recursos financeiros. A cidadania em saúde, alega Milewa ${ }^{7}$, assume que o Estado é capaz de garantir a igualdade do direito à saúde. $\mathrm{O}$ direito à saúde e a extensão deste direito é o resultado do grau de inclusão da cidadania em um sistema de saúde. Em outras palavras, a equidade é o primeiro dos direitos dos cidadãos ${ }^{55}$.

Neste prisma, as instituições de saúde são criticadas pelo fato de não brindar oportunidades adequadas e mecanismos apropriados aos cidadãos que não dispõem de recursos econômicos e culturais para participar nos processos de tomada de decisões ${ }^{32,50,56}$. Recomenda-se, portanto, a implementação de dispositivos adicionais para se alcançarem grupos distintos de cidadãos ${ }^{24}$, de forma a garantir uma adequada representação dos grupos sociais desfavorecidos ${ }^{57}$.

\section{Influência e efetividade da participação}

Apesar de a participação representar um valor em si mesma, na medida em que exerce uma relevante função de educação à democracia ${ }^{58}$, é importante contemplar também os resultados obtidos pela ação participativa ${ }^{41,59}$. No caso dos sistemas de saúde, os mecanismos participativos, tanto os deliberativos como os mais tradicionais, devem mostrar a capacidade de gerar recomendações e exercer algumas formas de influência nos decisores políticos ${ }^{25,55,60}$. Blondiaux e Sintomer ${ }^{61}$, por exemplo, têm assinalado a debilidade da relação entre democracia deliberativa e processos de decisão: "Porque ser envolvidos se depois falta a perspetiva da ação? Como convencer as pessoas a participar sem garantir que seus pontos de vista serão utilizados?". Na mesma linha, Fung e Wright ${ }^{41}$ afirmam que os investigadores e os profissionais deveriam avaliar as experiências de participação não somente pela qualidade dos processos, mas também pelos efeitos. Esta é a maior preocupação de muitos estudiosos que identificam a avaliação dos dispositivos de envolvimento dos cidadãos como uma área ainda descuidada na literatura sobre participação social, inclusos os métodos deliberativos ${ }^{30,35,36}$. A necessidade de estudos que demonstrem a efetividade dos mecanismos participativos é essencial para garantir o uso apropriado dos recursos públicos, incluindo o tempo e os esforços dos cidadãos que raramente foram contabilizados entre os gastos da participação. Esta preocupação não era percebida nas investigações publicadas nos anos 90, quando o desafio era o de legitimar a prática da participação e realçar os benefícios desta prática.

Sobre isto, é muito interessante a revisão de Crawford et al. ${ }^{62}$ dos artigos publicados entre Janeiro 1966 e Outubro de 2000, uma vez que, dos 42 artigos considerados na análise, nenhum revelou preocupação em "avaliar os efeitos do envolvimento dos pacientes na saúde, na qualidade dos cuidados prestados ou na satisfação de quem os utiliza”. Para os autores, isto significa que os efeitos da participação sobre a qualidade e efetividade dos serviços são, portanto, desconhecidos.

Recentemente, também Mitton et al. ${ }^{32}$ empreenderam uma análise relevante ao nível de análises empíricas registradas entre 1981-2006, mais concretamente sobre a implicação dos usuários na definição das prioridades em saúde e na distribuição de recursos. Os resultados da análise de 175 artigos confirmaram, uma vez mais, o escasso interesse pela avaliação da efetividade da participação em saúde visto que: i) dois terços dos artigos analisados concluem que o processo participativo se considera bem-sucedido apesar da escassez da avaliação; ii) somente em 6\% dos casos se admitem que o envolvimento dos usuários foi mal sucedido; iii) 75\% das avaliações realizadas adotaram critérios baseados no 'processo' participativo e somente em $25 \%$ critérios 
baseados nos resultados da participação; iv) as experiências consideradas bem-sucedidas não aparecem relacionadas com os processos de avaliação efetuados.

A avaliação das experiências participativas dos cidadãos é ainda mais urgente face à sua grande proliferação nos últimos anos, sobretudo a partir de novos métodos de promoção da participação. É também escasso o conhecimento que dispomos sobre a qualidade e efetividade da participação em saúde e se os distintos métodos permitem alcançar os diversos objetivos incluídos no conceito de participação pública. Já no final dos anos 70, Rosener ${ }^{63}$ observou que "a falta de conhecimento sobre a efetividade da participação está provavelmente relacionada com o fato de que poucos estudiosos reconhecem esta complexidade". Mais tarde, Rosener ${ }^{64}$ veio a identificar quatro problemas inerentes a realização deste tipo de avaliação: i) o conceito de participação é complexo e está carregado de valores; ii) não há muitos critérios para julgar o êxito e os fracassos de uma estratégia de participação; iii) não há acordo sobre os métodos de avaliação; iv) os instrumentos de medida são poucos fiáveis ${ }^{64}$.

Trinta anos depois, Burton ${ }^{65}$ reitera o mesmo questionamento sobre a dificuldade em avaliar um conceito complexo como a participação pública, que nem sempre é suficientemente definido e compartilhado. Seguramente, a dificuldade de desenhar modelos apropriados e rigorosos de avaliação é o fator responsável pelo ainda escasso conhecimento sobre impacto dos diferentes mecanismos de participação ${ }^{65}$. De fato, antes de construir uma estratégia apropriada de avaliação da efetividade, torna-se necessário clarificar o que entendemos por participação pública e como seus benefícios são definidos teoricamente e empiricamente.

Para isso, no entanto, é importante compreender o que constitui um bom resultado de uma prática participativa, assim como os processos que contribuem para alcançá-lo ${ }^{66}$. Por outras palavras, a avaliação da efetividade requer uma definição de êxito para as distintas práticas de envolvimento dos cidadãos ${ }^{67}$. Nesse sentido, não é suficiente desenvolver uma definição única de êxito, já que na arena sanitária existe uma multiplicidade de atores envolvidos e uma diversidade de perspectivas sobre os objetivos da participação. Por exemplo, em relação às funções que devem desempenhar os representantes dos cidadãos, cabe perguntar: Devem participar na difusão das informações? Devem expressar suas opiniões sobre o que já está decidido? Ou devem ser envolvidos na tomada de decisões?

Infelizmente, estas questões conceituais e metodológicas têm recebido pouca consideração por parte da literatura acadêmica e isto tem permitido que qualquer atividade de envolvimento dos cidadãos pudesse ser considerada exitosa ${ }^{66}$.

As reflexões de muitos investigadores sobre a avaliação da participação convergem na necessidade de definir o conceito de efetividade e os critérios mais adequados para a avaliação das experiências de participação $0^{53,68,69}$. Muitas das definições encontradas reconhecem a complexidade e a multidimensionalidade do sucesso destes processos e adotam, consequentemente, múltiplos critérios: critérios baseados no processo, no resultado ou em ambos. Na revisão efetuada por Rowe et al. ${ }^{69}$, por exemplo, cerca da metade dos estudos publicados adotaram critérios de resultado e a outra metade critérios baseados no processo.

Como se pode observar na literatura sobre o assunto, as preocupações sobre o impacto da participação social e da falta de práticas de avaliação entraram, há alguns anos, no debate acadêmico e profissional. No entanto, ainda hoje é possível notar um desequilíbrio entre a quantidade de tempo, de recursos e de energia que os governos investem para envolver os cidadãos e os representantes da sociedade civil nos processos de decisão pública e a atenção dispensada à avaliação da eficácia de tais esforços ${ }^{70}$. Torna-se, portanto, cada vez mais urgente desenvolver um modelo robusto e confiável para avaliar o impacto da participação social.

\section{Conclusões}

Na perspetiva da governança, o Estado deve redefinir a relação com a sociedade civil criando canais permanentes de negociação que promovam a cidadania ativa através da institucionalização da participação cidadã nas decisões do governo.

Neste sentido, muitos países já implementaram métodos e dispositivos (conselhos, comitês, conferências, fóruns, etc.), para incentivar a participação de representantes das associações e da sociedade civil na elaboração de políticas públicas. No contexto dos sistemas de saúde, este processo de reconhecimento dos direitos dos cidadãos remonta aos anos 70, quando a Organização Mundial de Saúde e a UNICEF apontaram a participação como uma das diretrizes essenciais para garantir a Saúde para Todos até o Ano $2000^{71}$. 
Hoje, olhando para a literatura sobre a participação em saúde, pode-se observar que há um amplo consenso sobre a importância de envolver os cidadãos em diferentes momentos do processo de produção de saúde. No entanto, apesar de o tema da participação ser um dos mais abordados pela literatura em saúde ${ }^{72}$, a análise da literatura dos últimos anos tem mostrado uma contradição entre o discurso político (e, às vezes, a retórica) sobre a participação dos cidadãos e a prática das instituições de saúde ainda pouco sensíveis às contribuições do seu ambiente social. Para explicar essa incongruência, a literatura enfoca vários aspetos problemáticos que são associados tanto às modalidades de funcionamento dos sistemas de saúde (ainda permeados por uma cultura organizacional burocrática) como ao insuficiente nível de capacitação (empowerment) necessário para apoiar o processo de envolvimento dos cidadãos ${ }^{56,73}$. Muitos estudos têm demonstrado que os mesmos representantes dos usuários e das associações de pacientes também encontram algumas dificuldades no desempenho das suas funções de representação dos cidadãos. Estas situações críticas, obviamente, contribuem para redimensionar ainda mais o potencial da cidadania, entendida como prática social que - como observamos nas seções anteriores - confere aos cidadãos, titulares de direitos, a capacidade de pôr suas próprias necessidades e perspetivas de análise no centro do debate político e dos processos de decisão.

Neste prisma, torna-se premente desenvolver uma série de reformas, no âmbito dos sistemas de saúde, para dar novo impulso e vigor ao projeto de cidadania, entendido como participação ativa no processo de decisão e na definição de objetivos coletivos. Para este fim, é importante, antes de tudo, superar a abordagem individualista típica da consumer satisfaction, muito utilizada nos últimos anos em projetos de melhoramento da qualidade do cuidado em saúde e que têm demonstrado a existência de diferentes formas de entender a participação dos cidadãos. Eles podem estar envolvidos individualmente e passivamente, como respondentes de um questionário para levantar seus níveis de satisfação com os serviços de saúde, mas - como argumenta Crou$\mathrm{ch}^{2}$ - neste caso trata-se de "um exercício muito pobre, se o objetivo é desenvolver um espaço de cidadania ativa". A própria introdução da Carta do Paciente (Patient's charter) - como mostram as experiências internacionais - tem contribuído para a redefinição dos usuários como consumidores individuais e não como cidadãos com uma voz coletiva.

O sentido de cidadania é desenvolvido - escreveu Valelly ${ }^{74}$ - por meio da participação dos cidadãos em associações e ações cívicas, discussão, deliberação e análise de questões que afetam a comunidade. Cidadania, continua o autor, exige um aumento do diálogo coletivo e o reforço das relações entre indivíduos e grupos.

Esta perspectiva desejável, no entanto, pressupõe a capacidade de deter o processo de "comercialização da cidadania" que, de acordo com Crouch $^{17}$, está a devolver ao mercado uma gama de serviços públicos (incluindo os de saúde) que lhe tinha sido subtraído em meados do século XX. No caso da saúde, são óbvias as distorções resultantes de um sistema que deu prioridade ao critério da eficiência, em vez do critério da equidade, e que tem contribuído de forma significativa para acelerar a diluição da cidadania.

Como vimos no decorrer de nossa análise, a presença de grupos sociais menos favorecidos e de cidadãos que não dispõem de recursos econômicos e culturais para participar nos processos de tomada de decisões, e a expansão da área das desigualdades minam as pré-condições para o desenvolvimento da prática da participação e da cidadania. Nesse sentido, existem fortes laços entre as questões da igualdade, dos direitos e da participação.

\section{Agradecimentos}

Ao doutorando Ronaldo Teodoro dos Santos (PUC Minas), pelos preciosos comentários, e à doutoranda Edilene Mendonça Bernardes (USP Ribeirão Preto) e à mestre Edilma Maria Marcos do Nascimento pela revisão do texto em português. 


\section{Referências}

1. Habermas J. Further reflections on the Public Sphere. In: Calhoun $\mathrm{C}$, organizador. Habermas and the Public Sphere. Cambridge: The MIT Press; 1992.

2. Crouch C. La ampliación de la ciudadanía social y económica y la participación. In: García S, Lukes S, organizadores. Ciudadanía, justicia social, identidad y participación. Madrid: Siglo Veintiuno; 1999. p. 257-285.

3. Santos BS, Avritzer L. Introdução: para ampliar o cânone democrático. In Santos BS, organizador. Democratizar a democracia. Os caminhos da democracia participativa. Rio de Janeiro: Civilização Brasileira; 2002. p. 39-82.

4. Marshall TH. Cidadania Classe social e Status. Rio de Janeiro: Zahar Editores; 1967.

5. Brannan T, John P, Stoker G. Active citizenship and effective public services and programmes: How can we know what really works? Urban Studies 2006; 43(5/6): 993-1008.

6. Harrison S, Mort M. Which champions, which people? Public and user involvement in health care as a technology of legitimation. Social Policy and Administration 1998; 32(1):60-70.

7. Milewa T. Local Participatory Democracy in Britain's Health Service: Innovation or Fragmentation of a Universal Citizenship? Social Policy \& Administration 2004; 38(3):240-252.

8. Milewa T, Valentine J, Calnan M. Community participation and citizenship in British health care planning: narrative of power and innovation in the changing welfare state. Sociology of Health and Illness 1999; 2(4):445465.

9. Calnan M, Gabe J. From consumerism to partnership? Britain's national health service at the turn of the century. Int J Health Serv 2001; 31(1):119-131.

10. Donati P. La cittadinanza societaria. Laterza: Bari; 2000.

11. Turner B. Outline of a Theory of Citizenship. Sociology 1990; 24(2):189-217.

12. Carvalho JM. Cidadania no Brasil: O longo caminho. Rio de Janeiro: Civilização Brasileira; 2002.

13. Ellison N. Towards a New Social Politics: Citizenship and Reflexivity in Late Modernity. Sociology 1997; 31(4):697-717.

14. Young IM. Polity and Group difference: A Critique of the Ideal of Universal Citizenship. Ethics 1989; 99(2):250-274.

15. Barbalet J. Citizenship: Rights, Struggle and Class Inequality. London: Open University Press; 1988.

16. Lister R. Citizen in action: citizenship and community development in a Northern Ireland context. Community Development Journal 1998; 33(3):226-235.

17. Crouch C. Postdemocrazia. Bari: Laterza; 2003.

18. Rose N. The Politics of Life Itself. Biomedicine, Power, and Subjectivity in the Twenty-First Century. Princeton: Princeton University Press; 2007.

19. Petryna A. Biological Citizenship: The Science and Politics of Chernobyl-Exposed Populations. OSIRIS 2004; 19:250-265.

20. Nunes JA. Saúde, direito à saúde e justiça sanitária. Revista Crítica de Ciências Sociais 2009; 87:143-169.

21. Osler A, Starkey H. Changing citizenship. Democracy and Inclusion in Education, Maidenhead: Open University Press; 2005.
22. Cornwall A, Romano J, Shankland A. Brazilian Experience of Participation and Citizenship. A critical look. Brighton: Institute of Development Studies - IDS; 2008. Discussion paper 389.

23. Wharf Higgins J. Citizenship and empowerment: a remedy for citizens participation in health reform. Community Development Journal 1999; 31(4):287-307.

24. Labra ME. Política Nacional de Participação na Saúde: entre a utopia democrática do controle social e a práxis predatória do clientelismo empresarial. In: Fleury S, Lobato LVC, organizadores. Participação democracia e saúde. Rio de Janeiro: CEBES; 2009, p. 176-203.

25. Escorel S, Moreira MR. Desafios da participação social em saúde na nova agenda da reforma sanitária: democracia deliberativa e efetividade. In: Fleury S, Lobato LVC, organizadores. Participação democracia e saúde. Rio de Janeiro: CEBES; 2009. p. 229-247.

26. Cornwall A. Deliberating Democracy: Scenes from a Brazilian Municipal Health Council. Politics \& Society 2008; 36(4):508-531.

27. Barnes M, Coelho VS. Social participation in health in Brazil and England: inclusion, representation and authority. Health Expect 2009; 12(3):226-236.

28. Avritzer L. Teoria democratica e deliberação pública. Lua Nova 2000; 50:25-47.

29. Elster J. Deliberative Democracy. Cambridge: Cambridge University Press; 1998.

30. Abelson J, Forest PG, Eyles J, Smith P, Martin E, Gauvin FP. Deliberations about deliberative methods: issues in the design and evaluation of public participation process. Soc Sci Med 2003; 57(2):239-251.

31. Habermas J. Teoria dell'agire comunicativo, I. Razionalità nell'azione e razionalizzazione sociale, II. Critica della ragione funzionalistica. Bologna: Il Mulino; 1997.

32. Mitton C, Smith N, Peacock S, Evoy B, Abelson J. Public participation in health care priority setting: A scoping review. Health Policy 2009; 91(3):219-228.

33. Chambers S. Deliberative Democratic Theory. Annual Review of Political Science 2003; 6:307-326.

34. Delli Carpini MX, Cook FM, Jacobs LR. Public Deliberation, Discursive Participation, and Citizen Engagement: A review of the Empirical Literature. Annual Review of Political Science 2004; 7:314-344.

35. Lehoux P, Daudelin G, Demers-Payette O, Boivin A. Fostering deliberations about health innovation: What do we want to know from publics? Soc Sci Med 2009; 68(11):2002-2009.

36. Church J, Saunders D, Wanke M, Pong R, Spooner C, Dorgan M. Citizen participation in health decision-making: past experience and future prospects. $J$ Public Health Policy 2002; 23(1):12-32.

37. Davies S, Elisabeth S, Hanley B, New B, Sang B. Ordinary Wisdom. Reflections on an experience in citizenship and health. London: King's Fund; 1998.

38. Iridale R, Longlay M. From passive subject to active agent: The potential of Citizens' Juries for nursing research. Nurse Educ Today 2007; 27(7):788-795.

39. Gooberman-Hill R, Horwood J, Calnan M. Citizens' juries in planning research priorities: process, engagement and outcome. Health Expect 2008; 11(3):272-281.

40. Rigge M. Does public opinion matter? Health Serv J 1995; 105(5469):26-27. 
41. Fung A, Wright O. Deepening Democracy: Innovations in Empowered Participatory Governance". Politics Society 2001; 29:5-41.

42. Labra ME, Figueiredo JSA. Associativismo, participação e cultura cívica. O potencial dos conselhos de saúde. Cien Saude Colet 2002; 7(3):537-547.

43. Guizardi FL, Pinheiro R. Dilemas culturais, sociais e políticos da participação dos movimentos sociais nos Conselhos de Saúde. Cien Saude Colet 2006; 11(3):797805.

44. Bispo Júnior JP, Gerschman S. Potencial participativo e função deliberativa: um debate sobre a ampliação da democracia por meio dos conselhos de saúde. Cien Saude Colet 2013; 18(1):7-16.

45. Lomas J. Devolving authority for health care in Canada's provinces. 4. Emerging issues and prospects. CMAJ 1997; 156(6):817-823.

46. Bovenkamp HM, Trappenburg MJ, Grit KJ. Patient Participation in collective healthcare decision making: the Dutch model. Health Expectf 2009; 13(1):73-85.

47. Serapioni M, Romaní O. Potencialidades e desafios da participação em instâncias colegiadas dos sistemas de saúde: os casos de Itália, Inglaterra e Brasil. Cad Saude Publica 2006; 22(11):2411-2422.

48. Martin GP. Representativeness, legitimacy and power in public involvement in health-service management. Soc Sci Med 2008, 67(11):1757-1765.

49. Contandriopoulos D. A sociological perspective on public participation in health care. Soc Sci Med 2004 58(2):321-330.

50. Frankish CJ, Kwan B, Ratner PA, Warf Higgins J, Larsen C. Challenges of citizen participation in regional health authorities. Soc Sci Med 2002; 54(10):1471-1480.

51. Van Stralen CJ, Lima AMD, Sobrinho DF, Saraiva LES, Van Stralen TBS, Belisario SA. Conselhos de saúde: efetividade do controle em municípios de Goiás e Mato Grosso do Sul, Cien Saude Colet 2006; 11(3):621-632.

52. Cotta RMM, Cazal MM, Martins PC. Conselho Municipal de Saúde: (re)pensando a lacuna entre o formato institucional e o espaço de participação social. Cien Saude Colet 2010; 15(5):2437-2445.

53. Timotijevic L, Raats MM. Evaluation of two methods of deliberative participation of older people in food-policy development. Health Policy 2007; 82(3):302319.

54. Miller D. Citizenship and Pluralism. Political Studies 1995; XLIII:432-450.

55. Altieri L. Valutazione e partecipazione. Metodologie per una ricerca interattiva e negoziale. Milão: Franco Angeli; 2009.

56. Tritter JQ, McCallum A. The snakes and ladders of user involvement: moving beyond Arnstein. Health Policy 2006; 76(2):156-158.

57. Wakeford T. Citizens Juries: a radical alternative for social research, Social Research Update 2002; 37:1-5.

58. Paterson C. Participation and democratic theory. Cambridge: Cambridge University Press; 1970.

59. Ardigò A. La partecipazione nel servizio sanitario nazionale. La ricerca sociale 1979; 20:7-19.
60. Entwistle VA. Editorial. Public involvement in health service governance and development: questions of potential for influence. Health Expect 2009; 12(1):1-3.

61. Blondiaux L, Sintomer Y. L'impératif délibératif. Politix 2002; 15(57):17-35.

62. Crawford MJ, Rutter D, Manley C, Weaver T, Bhui K, Fulop N, Tyrer P. Systematic review of involving patients in the planning and development of health care. BMJ 2002; 325(7375):1263.

63. Rosener JB. Citizen Participation: Can we measure its effectiveness? Public Administration Review 1978; 38(5):457-463.

64. Rosener JB. User-oriented evaluation: A new way to view citizen participation. Journal of Applied Behavioral Science 1981; 17(4):583-596.

65. Burton P. Conceptual, Theoretical and Practical Issues in Measuring the Benefits of Public Participation. Evaluation 2009; 15(3):263-284.

66. Rowe G, Frewer LJ. Public Participation methods: A Framework for Evaluation. Science, Technology \& Human Value 2000; 25(1):3-29.

67. Chess C, Purcell K. Public participation and the environment: Do we know what works? Environmental Science \&Technology 1999; 33(16):2685-2691.

68. Halvorsen KE. Assessing the Effects of Public Participation. Public Administration Review 2003; 63(5):535543.

69. Rowe G, Marsh R, Frewer LJ. Evaluation of a Deliberative Conference. Science, Technology and Human Value 2004; 29(1):88-121.

70. Organization for Economic Co-operation and Development (OECD). Evaluating public participation in policy-making. Paris: OECD Publications; 2005.

71. World Health Organization (WHO). Alma Ata. Primary Health Care. Report of the Conference. Geneva: WHO; 1978.

72. Kondilis BK, Kiriaze IJ, Athanasoulia AP, Falagas ME. Mapping Health Literacy Research in the European Union: A Bibliometric Analysis. PLOS ONE 2008; 3(6):1-6.

73. Avery BY. Who does the work of public health? Am J Public Health 2002; 4(92):570-576.

74. Valelly R. Reconnected citizenship. In: Ingram HM, Rathgeb Smith S, organizadores. Public policy for democracy. Washington: The Brookings Institution; 1993. p. 240-255.

Artigo apresentado em 15/03/2013

Aprovado em 25/03/2013

Versão final apresentada em 26/03/2013 
